\title{
Progress and Pitfalls: Are the BRIC Countries' Social Agendas Constraining Their Economic Growth?
}

\author{
Jacira Werle Rodrigues \\ School of Management, Business School \\ University of New South Wales (UNSW Sydney) \\ Australia
}

\begin{abstract}
This article elaborates a comparative analysis of current economic and social performance, and stage of development of the largest emerging markets, the BRIC countries. It aims to evaluate examine each country's performance, highlights commonalities and differences, and raises questions about the BRIC nations' ability to sustain their recent economic achievements. Multiple social and economic indicators, Gross Domestic Product (GDP), GDP per capita, Human Development Index (HDI), poverty rates, income inequality and Gini coefficient, between the period 2000-2015 have been analyzed. Findings suggest significant disparity between social and economic outcomes. Overall, wealth generation has been progressively improving; however, recent economic contraction signalizes a volatile context which, coupled with modest results in the social agenda, could be broadly detrimental to these countries sustainable development trajectory. It could be argued that these discrepant outcomes could potentially have been maximized by each country's governmental strategic decisions to address their internal challenges.
\end{abstract}

Keywords: BRIC, developing countries, economic growth, social development, sustainable development

\section{Introduction}

The rising importance of emerging economies in the global context is evident, in particular the role of the four largest countries: Brazil, Russia, India and China (the BRIC group). Even considering the recent economic deceleration, the group's position remains strong. According to data from the World Bank (2017), combined these four countries account for almost one quarter of the global Gross Domestic Product (GDP) and half of the world population. Their impressive economic growth in recent times provided the basis for economist Jim O'Neill (2001) to cluster them under the 'BRIC' label, with predictions (Lin \& Rosenblatt, 2012; Pricewaterhouse Coopers, 2017) that member countries will overtake the top positions in the global economic rankings by mid-century. Despite the BRIC countries' outstanding economic performance, there are queries in relation to their social development. Some researchers such as Haub (2012) suggest that more than wealth prosperity has to be achieved to ensure sustainable development on other dimensions. Remarkably, BRIC countries have generally performed poorly and remain far behind many other countries regarding human development, indicated by the United Nations Human Development Index (HDI) (United Nations Development Programme [UNDP], 2016). High poverty rates, poor infrastructure, ineffective use of resources, inadequate health services, unequal income distribution and social inequality are some of the issues yet to be effectively addressed (Elizaga, 2011; Epikhina, 2013; Heinz \&Tomenendal, 2012; Leahy, 2014; Sharma, 2012). Their recent stratospheric economic results raise questions in relation to how this wealth has been shared within their societies, the possible implications and how sustainable their development trajectories are. In reviewing recent progress, a pertinent question would be how the BRIC countries could ensure that economic growth and social development occur concomitantly. Considering this scenario, this article attempts to explore advancement dynamics in BRIC, identify positive initiatives, and highlight areas for improvement.

\section{Literature review}

The BRIC cluster has attracted the attention of researchers who have been trying to capture and interpret the reasons for and forecast their wealth creation. For instance, Thakur (2014) examines the magnitude of these countries' progress and draws attention to the fact that countries such as China and India have doubled their economic output in less than 20 years, a result which took the United Kingdom 150 years and United States 50 years to reach. 
Lin and Rosenblatt (2012) emphasize BRIC's growing share in the world economy, which has been mirrored by a decline in the economies of the richest developed countries (i.e. Group of Seven). Furthermore, based on GDP as an indicator, the global economic performance of the BRIC cluster has accelerated significantly since 2000 (Ministry of Statistics and Programme Implementation, 2016; World Bank, 2017). China is an indisputable outlier. Between 2000 and 2013, China by itself accounted for almost 25 per cent of the global GDP rise, followed by India with 5.8 per cent, Brazil with 3.1 per cent, and Russia with 1.8 per cent (Lin \& Rosenblatt, 2012). These impressive results provided evidence for researchers such as Lin and Rosenblatt (2012) to emphasize what was seen as a shift of global wealth from the traditional Group of Seven towards the BRIC countries. A similar line of argument, regarding the transition of global wealth, was presented by Das (2009), Carmody (2013) and evidenced by the International Monetary Fund (IMF, 2013). Nevertheless, despite these achievements, their ongoing and sustainable performance will need to be monitored, especially as financial circumstances and rates of development change, and disruption occurs in an increasingly uncertain economic environment.

It seems that, whilst the BRIC countries have been building significant levels of economic power, they have less effectively managed a range of internal issues - especially social problems that could negatively impact further sustainable economic and social development. Several researchers have identified multiple areas of concern. Examples of issues to be addressed by BRIC are high levels of income inequality and poverty (Elizaga, 2011; Epikhina, 2013; Sharma, 2012) and insufficient investment in key human development areas such as education and health (Awan, 2012; Leahy 2014; Yuan, 2011). Another concern pointed out by Das and Das (2013) and Gouvea, Montoya and Walsh (2013) which creates obstacles for wealth creation, often evident in developing countries, is corruption. Societies with weak institutions, poorly trained personnel and lack of transparency are some of the aspects identified by Das and Das (2013) negatively impacting progress when doing business with and in these countries. Others, for example, Szirmai (2005) and Elizaga (2011), have signaled that the low standard of living of a considerable section of the population in developing countries is one of the key impediments to these countries reaching developed status.

\section{Methodology and study approach}

This study has adopted a secondary data collection and analysis approach, coupled with in-depth examination of technical and academic literature. Macro-level comparative analyses were conducted on data gathered on the performance of the BRIC countries on key economic and social indicators. This made it possible to gauge their current development status and to hypothesize what their major obstacles are to further economic and social sustainable development. To understand comparative economic performance, secondary data collected was divided into sub-categories (Vartanjan, 2011) including total Gross Domestic Product (GDP), GDP per capita and GDP growth rates (Ministry of Statistics and Programme Implementation, 2016; World Bank, 2017). To assess comparative social development in the BRIC countries, several sub-sets of factors were assessed: Human Development Index (HDI), life expectancy, poverty rates and Gini coefficient (UNDP, 2016; World Bank, 2016; United States Central Intelligence Agency [CIA], 2016). Trends were analyzed to identify gaps and target areas for improved performance.

\section{Discussion of Findings}

\subsection{Outstanding economic progression}

Based on GDP as an indicator, the economic performance of the BRIC economies has accelerated since 2000 (World Bank, 2017). As evidenced in Figure 1, China has made the most significant improvement, jumping from US\$ 1.2 trillion to US\$ 11 trillion in fifteen years (2000-2015). In reviewing the data, it would be difficult to ignore that the Chinese economy is larger than the other three group peers combined. Although Brazil, Russia and India have a smaller GDP than China, they are stronger when compared to other emerging economies. India has become the second largest economy in the group, evolving from US\$ 462 billion to US\$2.2 trillion in the same period. Brazil and Russia come close behind; Brazil's total GDP grew from US\$ 655 billion to US\$ 1.8 trillion, whilst Russia increased its total GDP from US\$259 billion to US\$1.3 trillion (World Bank, 2017). 
The growth of each country's wealth can also be perceived when progressive data of annual per capita GDP is inspected in Figure 2. As evidenced, overall Russia and Brazil have performed better than the other two peers, growing steadily from 2000 until reaching a peak in 2010, subsequently declining. In Russia there was consistent improvement from US\$1,772 to US\$ 9,098 in the period 2000-2015.

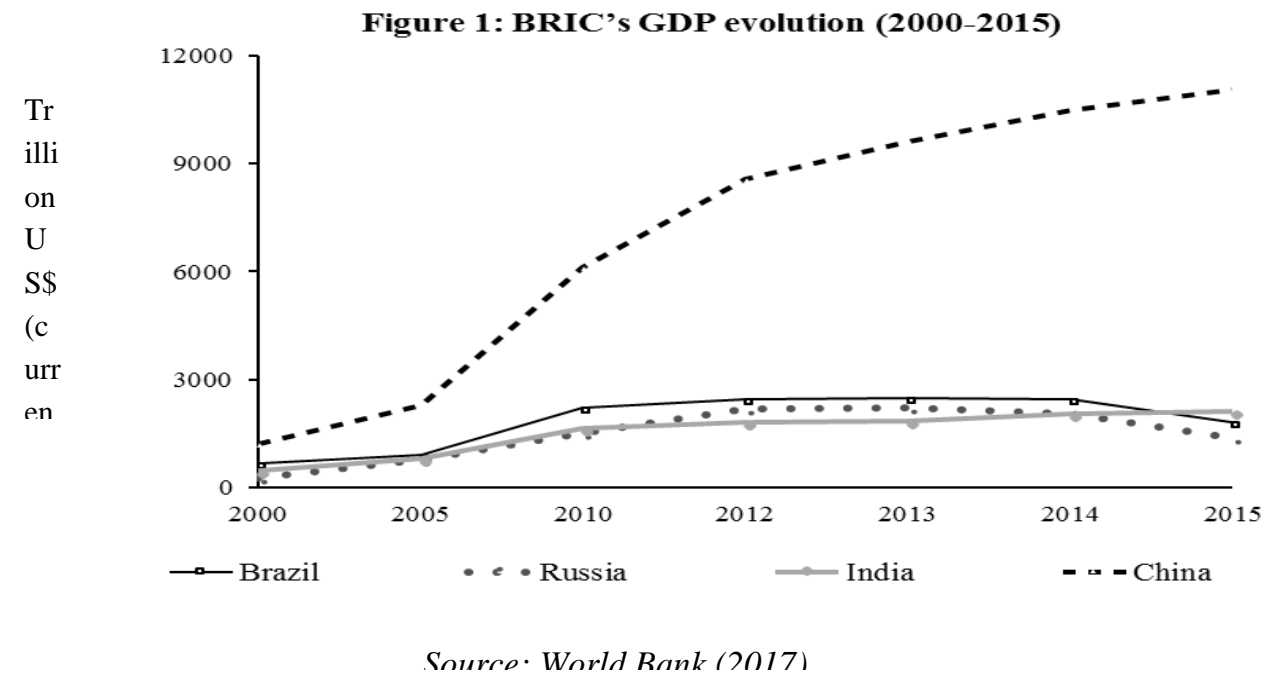

Brazil currently presents the second highest annual income per capita having lifted from US\$3,716 to US\$ 8,668, after a small contraction since 2010. The Chinese grew from US\$ 949 to US\$ 8,027, displaying the greatest improvement. The progress for India was also positive, but much more modest, rising from US\$ 451 to US\$

Figure 2: GDP per capita evolution (2000-2015)

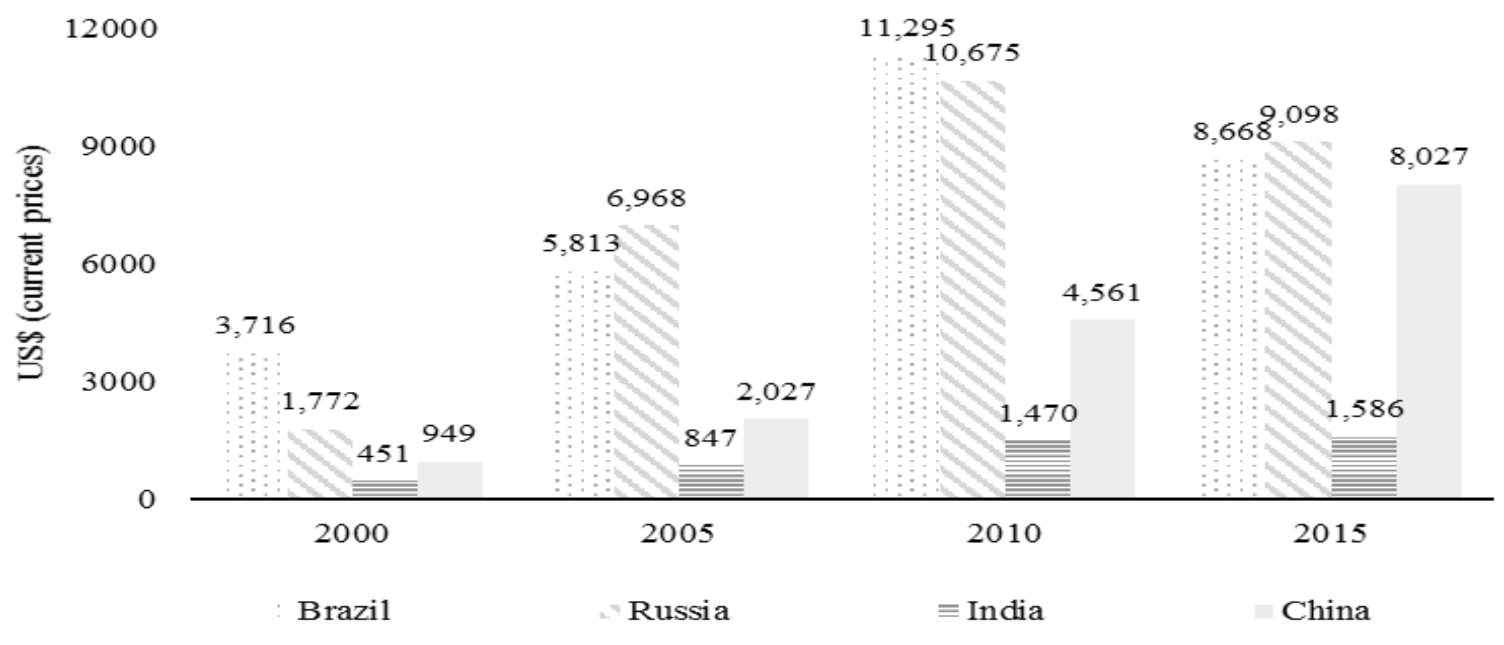

Source: Ministry of Statistics and Programme Implementation (2016)

1,586. Comparatively, currently India's GDP per capita is almost five times smaller than that of other three.

Examined together, these two GDP performance indicators provide evidence to conclude that the wealth created by the four BRIC countries has not directly reverted to the individual prosperity of their population. Previous researchers have discussed this point, for instance, in Müller's evaluation (2011, p.1616), in terms of individual income, the BRIC countries have "much catching up to do", with the conclusion that: "total economic growth has not always translated into people becoming wealthier". 
As signaled by Heinz \&Tommenendal (2012), the size of the BRIC internal market is small considering that people's potential buying power is limited in comparison to the advanced economies. The consequences of an insignificant internal market harming future economic growth have been witnessed currently when the external demand has reduced its pace (Didier, Kose, Ohnsorge, Ye, 2015; Kochhar, 2013). Moreover, people's reduced income impacts beyond economic prosperity, given that each person has a limited amount of income to ensure basic needs such as dwelling, health and education. The consequences for social impact are evident, reverberating to the economic domain and establishing a circle that is difficult to demolish.

Table 1: Comparative GDP annual growth rate (\%) (2000-2015)

\begin{tabular}{cccccccc}
\hline & $\mathbf{2 0 0 0}$ & $\mathbf{2 0 0 5}$ & $\mathbf{2 0 1 0}$ & $\mathbf{2 0 1 2}$ & $\mathbf{2 0 1 3}$ & $\mathbf{2 0 1 4}$ & $\mathbf{2 0 1 5}$ \\
\hline Brazil & 4.4 & 4 & 7.6 & 1.8 & 2.6 & 0.1 & -3.6 \\
Russia & 10 & 8.2 & 4.5 & 3.4 & 1.3 & 0.7 & -3.7 \\
India & 7.6 & 16.3 & 20.2 & 13.1 & 13.6 & 10.8 & 8.7 \\
China & 8.4 & 12.7 & 10.6 & 7.7 & 7.7 & 7.3 & 6.9 \\
\hline
\end{tabular}

Source: Ministry of Statistics and Programme Implementation (2016)

The robustness of BRIC's progression is impressive, but there are considerable variances in the pace of wealth creation, which can be perceived when assessing data of GDP growth rates (Table 1). Comparatively, in the period 2000-2015, Brazil presented a relatively slow annual growth rate starting from 4.4 per cent (2000) (Ministry of Statistics and Programme Implementation, 2016), the slowest in the group. It experienced a modest rise to 7.6 per cent (2010) and a sharp decrease in 2012 (1.8 per cent), with a subsequent modest recovery in 2013 (2.6 per cent), followed by a contraction of 3.6 per cent (2015). At no stage did it have the highest annual GDP growth in the cluster.

Differently, Russia showed relatively strong GDP annual growth in 2000 (10 per cent) and 2005 (8.2 per cent) but experienced a constant downward trend after that, facing retraction of 3.7 per cent (2015). On the other hand, the Indian economy maintained a positive overall trajectory during this period. With a starting rate of 7.6 per cent (2000), a strong increase reaching 16.3 per cent (2005), followed by a sharp rise to 20.2 per cent at its peak (2010). Subsequently, the Indian economy dropped to its current 8.7 per cent (2015). In the case of the Chinese economy, its annual growth rate fluctuated from 8.4 per cent (2000), increased to a plateau of 12.7 per cent (2005), subsequently dropping to 10.6 per cent (2010), and further to 7.7 per cent (2012) remaining stable at this point. Moreover, it is interesting to note an economic contraction in Brazil and Russia's economies from 2014 to 2015; meanwhile, with China and India presenting a comparatively slight reduction in their pace of evolution. A general overview of these annual growth rates presented by the BRIC countries in the period 2000-2015 provides evidence of how diverse their economic growth has been. Except for Russia and Brazil; countries including India and China presented a generally positive upward trend having some more accelerated peaks. Even with the positive trends, India had the most volatile trajectory with highly positive periods of growth and then subsequent reductions in the speed of progress.

Overall, one could question how solid their growth has been considering relatively inconsistent progression, as well as how sustainable these patterns are, and India's ability to promote economic progression throughout all of society.

\subsection{Modest social performance}

In contrast to the exceptional and positive economic evolution, the BRIC countries have been progressing modestly on social indicators. 
This can clearly be noted when analyzing the BRIC outcomes on the Human Development Index (HDI) (UNDP, 2016). Assessing measures of income, education and health, the HDI was created in 1990 by the United Nations (UN) as an alternative to the GDP measure, broadening the societal comprehension beyond economic dominance (UNDP, 2016). The UN recognizes the importance of financial progress, reinforcing the reasons why it should be continuous: "Economic growth is important, not for itself but for what it enables a country and people to do with the resources generated" (UNDP, 2014, p.26). Table 2 provides a summary of comparative data on social indicators and includes the HDI ranking (UNDP, 2016). The data indicates that Russia is best positioned on the HDI with a ranking of 49th in the world, followed by Brazil (79th), China (90th) and India (131st). Therefore, it could be argued that the social conditions of Russia are closest to those of developed nations, followed by Brazil and China.

Table 2: BRIC Social Development Indicators (2016)

\begin{tabular}{lccccc}
\hline & $\begin{array}{c}\text { Human } \\
\text { Development } \\
\text { Index (HDI) }\end{array}$ & $\begin{array}{c}\text { Life } \\
\text { expectancy }\end{array}$ & $\begin{array}{c}\text { Poverty } \\
\text { rates }\end{array}$ & $\begin{array}{c}\text { Gini } \\
\text { coefficient }\end{array}$ & $\begin{array}{c}\text { Income } \\
\text { inequality } \\
\text { ranking }\end{array}$ \\
\hline Brazil & 79 th & 75 & $4.9 \%$ & 54.7 & 17 th \\
Russia & 49 th & 70 & $<2 \%$ & 40.1 & 54 th \\
India & 131 st & 68 & $21.3 \%$ & 33.9 & 101 st \\
China & 90 th & 76 & $11.2 \%$ & 42.1 & 28 th \\
\hline
\end{tabular}

Sources: CIA (2016), UNDP (2016) and World Bank (2016)

India is an outlier in the cluster (UNDP, 2016) with an HDI ranking closer to countries in Sub-Saharan African.

Their poor performance on the HDI uncovers social challenges that could complicate further development. As identified in the literature and presented in Table 2, several social development challenges are still to be addressed. These include poverty and unequal income distribution (Chibba, 2011; Sharma, 2013); inadequate resources to address health concerns (Awan, 2012; Josh \& Yu, 2014; Leahy, 2014); and insufficient investment in education (Ardichvili, Zavyalova \& Minina, 2012; Yuan, 2011). Some scholars contend that the difficulties encountered in effectively addressing social issues (like poverty and income inequality) are linked to the recent reforms undertaken by the BRIC countries. The doubts relate to the social and economic consequences of liberalization, de-regulating policies and reduction of the government presence in society. For example, Das and Das (2013, p. 33) conclude "clearly, macroeconomic flexibility in a market-driven environment is not the best recipe for growth and stability for poverty reduction." Both poverty and income inequality have immediate and practical social and economic applications. Poverty rate statistics provide an overview of the problem (Table 2), which could be even more complicated. Clearly India faces the largest poverty challenge, with almost one-fifth of its population (21.3 per cent) living in extreme poverty (below US\$1.90 a day) (World Bank, 2016). China is second on this indicator, with around 11.2 per cent of its population considered living in extreme poverty, followed by Brazil with 4.9 per cent; Russia leads the group having the lowest poverty rate (below 2 per cent). Though the numbers are revealing as to the state of social development, the differences become far more significant when compared in real terms. For instance, India has the equivalent of the entire Brazilian population striving for daily survival. 
Another useful indicator to assess the living conditions of a population is the Gini coefficient. Based on the data in Table 2, trends show that despite having the lowest poverty rate, Brazil is one of the most unequal countries in the world, with a Gini coefficient of 54.7 (CIA, 2016) and, according to the United States CIA (2016) income inequality ranking, is the 17th most unequal country in the world. This is followed by China with a Gini index of 42.1 and a slightly lower rank as 28th in income inequality. Russia has the third highest Gini coefficient of the group (40.1) and a comparatively lower income inequality classification (54th). India has the lowest Gini coefficient of the group (33.9) and, consequently, is the least unequal in income distribution (101st). When interpreting the data, it is essential to exercise caution as statistics without proper interpretation and context can mask realities (Lamb, 2012). In this instance, although India has the lowest Gini coefficient and, as a result, lowest income inequality, in terms of wealth distribution among its people, the poverty statistics indicate that a significant proportion of India's population live in poverty and suffer the consequent social issues which are hidden in the Gini data. In the case of Brazil, Gini data and the position on the income inequality ranking show the enormous gap between high and low-income earners in the country.

To effectively comprehend the social impact of wealth concentration and limited social support, living conditions are reflected in life expectancy rates, with India ranked lowest amongst the BRIC nations (68 years), while the others have life expectancy rates of 70 (Russia), 75 (Brazil) and 76 (China) (UNDP, 2016). The intersection between poverty levels, life expectancy rates and social wellbeing is evident, as is the need for effective government intervention for improvements. Some members of BRIC have responded better than others in addressing issues identified on a range of social indicators in recent times. Below is a brief discussion on how each of them has been addressing these problems.

\subsection{Specific isssues and targeted solutions}

Brazil has sought to alleviate absolute poverty with the introduction of the "Bolsa Família" (Family Grant) initiative (UNDP, 2014; OECD, 2014). In a program introduced to reduce poverty and income inequality, the federal government has transferred cash to poor families on the condition that children maintain appropriate levels of school attendance and undertake regular health checks. As suggested by Tepperman (2016) for a poor family, a small sum makes a considerable difference. Each registered family receives $\$ 65$ a month on average. The program benefits a total of 50 million people, or 25 per cent of the country's population.

Russia has been confronted with some challenges in relation to human development, poverty and income inequality in recent times. As indicated by Ardichvili et al. (2012), when the HDI was launched in 1990, Russia was among 25 countries with the highest levels of development in the world. Immediately after, with the collapse of the Soviet Union (1991), Russia's performance on the HDI sharply declined and subsequently rose to a medium level (49th). The results in the HDI were able to capture the instability of the transitioning years between the communist political regime into the capitalist regime.

India has the highest level of poverty compared to its BRIC peers, with the most vulnerable being women and children concentrated in rural areas (UNDP, 2014; World Bank, 2016b). The Indian government has adopted strategies to boost employment and wages in rural areas, and provide food with subsided prices (National Food Security Act) since July 2013, with the subsided products program reaching 67 per cent of the population (OECD, 2014). However, such actions fall far short of the strategies required to improve income distribution in India. Another problem is that the fragmented government social protection system is only able to reach certain regions and particular population groups but misses most others (OECD, 2011). As several of the indicators have demonstrated, India has a long way to go to achieve beneficial social outcomes for its population.

China has been successful in reducing poverty, though it has not been as effective in reducing income inequality and distribution. Figures in the HDI report (UNDP, 2016) indicate that the growth of consumption levels of the poorest 40 per cent of the Chinese population is positive, but it has been growing at a slower rate than that of the rest of the population. Compared to the other BRIC countries, such as Russia and India, China has been able to achieve substantial economic growth but has seen a rise in wealth inequality. Guangjin (2013, p. 496) asserts that "the income inequality shows that only the highest income group has been continuously adding to their share of the total income, while the share of all other groups has been declining", especially in rural and regional areas.

\section{Possible implications}

Irrefutable evidence from macro indicators shows that the BRIC countries have achieved economic prosperity. 
However, when undertaking a detailed analysis, differences are perceptible in how the prosperity has spread across society. Poverty rates are considerably elevated (especially in India) in a context of higher income inequality (mainly in Brazil and in China). The division of the wealth created seems to be a chronic issue in the BRIC countries. This can be verified by the low GDP per capita and, consequently, small aggregated internal market in each of these countries (Heinz \&Tommenendal, 2012; Kochhar, 2013). Given the low rates of income per capita in the developing countries, compared to those in advanced economies, there are potential consequences for the buying power in local BRIC markets. In addition, high levels of income inequality also contributed to restricted access to health, education, and the general wellbeing of people. Other obstacles, not discussed in this paper, include access to basic infrastructure, demographic realities and environmental treaties that could directly impact the economic progression of BRIC. It seems that each BRIC country has unique internal social and economic demands that must be faced on their path to progress. Their unattended social agendas are a potential threat to wealth creation, but not the only one, considering their economies have shown signs of trembling recently.

\section{Acknowledgements}

This paper is based on author's initial key notes presented at the Australian and New Zeland International Business Academy Conference (2015). The author is grateful for comments provided by Professor Prem Ramburuth which had enriched the initial development of this paper.

\section{References}

Ardichvili, A., Zavyalova, E. \& Minina, V. (2012). Human capital development: comparative analysis of BRICs. European Journal of Training and Development, 26 (2/3), 213-233.

Awan, A.G. (2012). Diverging trends of human capital in BRIC countries. International Journal of Asian Social Science, 2 (12), 2195-2219.

Carmody, P. (2013). The rise of the BRICS in Africa, the geopolitics of South-South relationships. London, England: Zed Books.

Chibba, M. (2011). The millennium development goals: key current issues and challenges. Development Policy Review, 29 (1), 75-90.

Das, D.K. (2009). Globalization and an emerging global middle class. Economic Affairs, 29 (3), 89-92.

Das, M. \& Das, S.K. (2013). Economic growth and income disparity in BRIC: theory and evidence. London, England: World Scientific.

Didier, T., Kose, M., Ohnsorge, F. L.; Ye, L. (2015). Slowdown in emerging markets: rough patch or prolonged weakness? Policy Research Note. Washington, DC, USA: World Bank Group.

Elizaga, R.S. (2011). Inequality, exclusion and poverty in Latin America: the vast social debt of neoliberalism. In B. Rehbein (Ed.), Globalization and inequality in emerging societies (pp.50-67). New York, USA: Palgrave Macmillan.

Epikhina, Y. (2013). Income inequality in Russia. In P. Li; M.K. Gorshkov; C. Scalon, \& K. L. Sharma (Eds.), Handbook on Social Stratification in the BRIC Countries: Change and Perspective (pp. 439 - 454). London: World Scientific.

Guangjin, C. (2013). Structural characteristics and trends of income inequality in China. In P. Li; M.K. Gorshkov; C. Scalon, \& K. L. Sharma (Eds.), Handbook on Social Stratification in the BRIC Countries: Change and Perspective (pp. 482 - 498). London, England: World Scientific.

Gouvea, R., Montoya, M. \& Walsh, S. (2013). How the corruption quadruple helix affects BRIC: a case study of corruption in big emerging economies. Journal of Politics and Law, 6 (2), 1-12.

Haub, C. (2012, April). The BRIC Countries [Web blog post]. Retrieved from http://www.prb.org/Publications/Articles/2012/brazil-russia-india-china.aspx

Heinz, D. B. \& Tomenendal, M. (2012). The emerging market hype-putting market size and growth in BRIC countries into perspective. Critical Perspectives on International Business, 8 (3), 241-258.

Kochhar, K. (2013). Emerging markets: prospects and challenges. Policy Brief. Washington, DC: International Monetary Fund.

International Monetary Fund (IMF). (2013). World Economic Outlook: Transitions and Tensions. Washington, USA: International Monetary Fund. 
Josh, D.K. \& Yu, B. (2014). Political determinants of public health investments in China and India. Asian Politics \& Policy, 6 (1), 59-82.

Lamb, E. (2012). Ask Gini: how to measure inequality. Scientific American. Retrieved from http://www.scientificamerican.com/article/ask-gini/

Leahy, J. (2014). Struggling hospitals a symptom of all that ails Brazil. Financial Times, Retrieved from http://www.ft.com/intl/cms/s/0/5ea15d38-dfd3-11e2-bf9d-00144feab7de.html\#axzz3DqlwHSEY

Lin, J. Y. \& Rosenblatt, D. (2012). Shifting patterns of economic growth and rethinking development. Policy Research working paper; no. WPS 6040. Washington, DC, USA: World Bank.

Ministry of Statistics and Programme Implementation (2016). BRICS Joint Statistical Publication: Brazil, Russia, India, China and South Africa. New Delhi, India: Government of India.

Müller, M. (2011). New kids on the block: the rise of the BRIC and the reconfiguration of global economic ties. European Researcher, 15 (12), 1615-1625.

O’Neill, J. (2001). Building better global economic BRIC. Global Economics Paper, 66. New York, USA: Goldman Sachs.

Organization for Economic Co-operation and Development (OECD). (2011). Inequality in emerging markets. Paris, France: OECD Publishing.

Organization for Economic Co-operation and Development (OECD). (2014). Education at a glance 2014: OECD indicators. Paris, France: OECD Publishing.

Pricewaterhouse Coopers. (2017). The long view: how will the global economic order change by 2050? London, UK: PWC.

Sharma, R. (2012, June 10). Broken BRICs. Foreign Affairs, Retrieved from http://www.foreignaffairs.com/articles/138219/ruchir-sharma/broken-brics

Sharma, R. (2013). Poverty and income inequality in India's urban and rural areas. In P. Li; M. K. Gorshkov; C. Scalon, \& K.L. Sharma (Eds.). Handbook on Social Stratification in the BRIC Countries: Change and Perspective (pp.455 - 480). London: World Scientific.

Szirmai, A. (2005). The dynamics of socio-economic development: an introduction (2nd ed). Cambridge University Press, Cambridge.

Thakur, R. (2014). How representative are BRICS? Third World Quarterly, 35 (10), 1791-1808.

Tepperman, J. (2016). Brazil's Antipoverty Breakthrough. Foreign Affairs. Retrieved from https://www.foreignaffairs.com/articles/brazil/2015-12-14/brazils-antipoverty-breakthrough

United Nations Development Programme [UNPD]. (2016). Human Development Report 2016: Human Development for Everyone. New York, USA: United Nations Development Program.

United States Central Intelligence Agency (CIA) (2016, November 13). Distribution of Family Income Gini Index. Retrieved fromhttps://www.cia.gov/library/publications/the-world-factbook/rankorder/2172rank.html

Vartanjan, T.P. (2011). Secondary data analysis. New York, NY, USA: Oxford University Press.

World Bank (2016). The little data book 2016. Washington, DC, USA: World Bank.

World Bank. (2017, August 20). World Development Indicators Database, Retrieved from http://data.worldbank.org/indicator/NY.GDP.MKTP.CD?end=2015\&locations=BR-RU-IN-

CN\&start $=2000$

Yuan, S.J. (2011). Educational policies and economic growth in BRICs: comparative perspectives. Journal of USChina Public Administration, 8 (2), 1, 88-197. 